\title{
Current status of near-total laryngectomy: review
}

\author{
A K D'CRUZ, S SHARMA, P S PAI \\ Head Neck Services, Tata Memorial Hospital, Mumbai, India
}

\begin{abstract}
Concurrent chemoradiation is currently the accepted 'standard of care' for locally advanced laryngeal and hypopharyngeal cancers. However, there is a subset of patients not suitable for chemoradiation, in whom primary surgery is the best option. Speech preservation is of prime importance in these patients. Near-total laryngectomy is a voice-preserving procedure which can be considered as an alternative to total laryngectomy for selected patients with lateralised, locally advanced cancers of the larynx and hypopharynx. Although these patients are left with a permanent tracheostomy, lung-powered speech is maintained by way of a dynamic shunt created from the uninvolved tissues of the larynx. Since its first description in the early 1980s, the procedure has been shown by various authors to be oncologically sound, with high success rates. Unfortunately, the procedure has not gained wide acceptance due to perceived fears of surgical complexity. In this review, we discuss the various issues related to the procedure and we review the relevant literature.
\end{abstract}

Key words: Larynx Cancer; Laryngectomy; Speech

\section{Introduction}

There has been a paradigm shift in the management of patients with laryngeal and hypopharyngeal cancers. Concurrent chemoradiation is now the accepted 'standard of care' for these patients.

However, this treatment has its limitations, and benefits a select subset of patients with tumour stage (T) two, three and (in a small number) four cancers. Issues such as toxicity and poor tolerance may further preclude its routine use.

Therefore, there is still a definite group of patients with locally advanced cancer who require total laryngectomy as primary surgery, with ensuing loss of voice.

Following total laryngectomy, the tracheoesophageal puncture prosthesis is the 'gold standard' for speech restoration, with high success rates of up to 90 per cent. ${ }^{1-3}$ However, this technique has its limitations, namely complications, recurrent costs, device maintenance and physician dependence.

The near-total laryngectomy procedure is a useful alternative in patients who cannot avoid total laryngectomy. This procedure is as radical as total laryngectomy in terms of disease management, but makes use of the uninvolved contralateral laryngeal mucosa to fashion a dynamic shunt between the trachea and the neopharynx. Speech is lung-powered, and aspiration is avoided as the shunt is dynamic. Most importantly, the procedure has a high success rate (90 per cent), similar to that for tracheoesophageal puncture prosthesis, and once successful stays so for life, avoiding the recurrent costs associated with device change and maintenance.

Unfortunately, near-total laryngectomy has not gained worldwide acceptance despite numerous publications confirming its oncological safety and functional success. In this review, we discuss the procedure and review the relevant literature.

\section{Historical background}

Near-total laryngectomy was first described by Pearson et al. in the early $1980 \mathrm{~s}$ and is often referred to as the Pearson procedure. ${ }^{4}$ Other synonyms for the procedure are extended vertical hemilaryngectomy, subtotal laryngectomy and parsimonious laryngectomy. ${ }^{4-6}$ However the most commonly accepted terminology is the near-total laryngectomy.

\section{Prerequisites}

The near-total laryngectomy is ideal for patients who have unilateral laryngeal or pyriform disease limited to one side of the larynx, with sufficient uninvolved contralateral mucosa to be fashioned into a voice shunt.

The essential prerequisites for the procedure are: (1) a contralateral, uninvolved, mobile arytenoid and posterior half of the true vocal fold; and (2) a free interarytenoid and post-cricoid region, to ensure oncological safety of the resection margins. 


\section{Indications}

Near-total laryngectomy is suitable for all cases amenable to total laryngectomy, provided the above prerequisites are met. These include: $\mathrm{T}_{3}$ and $\mathrm{T}_{4}$ cancers of the larynx and pyriform fossa; patients whose radiotherapy has failed; and cases compatible with resection of the pharynx and limited areas of the tongue base, with or without flap reconstruction.

\section{Contraindications}

There are two main contraindications to near-total laryngectomy.

Involvement of the interarytenoid and postcricoid regions is an absolute contraindication, as this compromises the oncological safety of the resection.

Subglottic disease is not an absolute contraindication to the procedure, as the patient will have a permanent tracheostoma. However, extensive posterior subglottic extension will leave insufficient mucosa to fashion the shunt, and is thus a relative contraindication.

\section{Types}

Near-total laryngectomy is suitable for both laryngeal and hypopharyngeal cancers, and requires the resection of variable amounts of pharyngeal mucosa.

Three types of near-total laryngectomy have been described, based on the amount of pharyngeal resection, as follows: (1) near-total laryngectomy proper, used primarily for pure glottal lesions; (2) near-total laryngopharyngectomy, which involves partial resection of pyriform fossa mucosa with primary closure; and (3) extended near-total laryngopharyngectomy, which involves more extensive hypopharyngeal mucosa resection necessitating a flap repair.

\section{Technique}

A detailed description of the near-total laryngectomy procedure is beyond the scope of this article but has been well presented elsewhere. ${ }^{4,7}$

In terms of disease management, the procedure is as radical as total laryngectomy, with removal of the ipsilateral thyroid cartilage, ipsilateral cricoid cartilage segments and upper tracheal rings, in order to ensure wide excision of the tumour. The pre- and para-glottic spaces are removed along with the ipsilateral strap muscles and thyroid gland. The procedure is compatible with appropriate nodal dissection in the lateral and central compartments.

The success of the procedure is based on the creation of a dynamic myomucosal shunt using a laryngotracheal remnant, the diameter of which should fit a 14 French Foley's catheter. Therefore, the utmost care must be taken to preserve the contralateral recurrent laryngeal nerve and cricoarytenoid joint. The patient will be left with a permanent tracheostoma, as for total laryngectomy, and voicing will require the use of a thumb, as for the tracheoesophageal puncture prosthesis. The neopharynx is created either by primary closure using uninvolved pyriform fossa mucosa, or by augmented closure using an appropriate flap.

\section{Outcome measures}

The success of near-total laryngectomy is assessed based on its oncological safety, the presence and quality of post-operative speech, and complications.

\section{Oncological safety}

Throughout the literature, published cure rates confirm the safety of near-total laryngectomy, with control rates similar to those achieved with total laryngectomy.

In the largest series, 225 cases reported by Pearson et al., five-year local control rates were comparable to those for total laryngectomy. ${ }^{8}$

Aslan et al. studied 135 patients undergoing neartotal laryngectomy between 1989 and 2000, and analysed survival in 124 patients. ${ }^{9}$ Survival rates for $\mathrm{T}_{2}$, $\mathrm{T}_{3}$ and $\mathrm{T}_{4}$ cancers were $50,64.2$ and 73.3 per cent, respectively; these differences were not statistically significant.

The oncological safety of near-total laryngectomy was further demonstrated in a series of 137 patients with laryngeal and pyriform fossa cancer managed at our institution between 1989 and 1999. ${ }^{7}$ After a median follow up of 35 months, 70.1 per cent of patients were alive and disease-free. The local and locoregional recurrence rate was 7.3 per cent.

However, in cases with subglottic extension, the oncological safety of near-total laryngectomy is debatable. Aslan et al. compared results for supraglottic and transglottic cancers without subglottic extension to those for laryngeal cancer with subglottic extension. The five-year survival rates for transglottic, supraglottic and subglottic cancers were 65.8, 53.8 and 20 per cent, respectively. ${ }^{10}$ The presence of subglottic extension increased the risk of local and peristomal recurrence. Thakar et al. also found inferior functional outcomes for near-total laryngectomy in cases with subglottic extension. ${ }^{11}$ In their 1998 series, Pearson et al. did not find any local recurrence in cases with subglottic extension. ${ }^{8}$ However, extensive subglottic spread, particularly posteriorly, precludes the use of this procedure and is one of its relative contraindications.

Near-total laryngectomy is possible even in the presence of cervical lymphadenopathy. Aslan et al. found survival rates for node stage $(\mathrm{N})$ one and two disease of 84.2 and 66.7 per cent, respectively. ${ }^{9}$ All patients with $\mathrm{N}_{3}$ disease died, which is understandable given the advanced nature of the disease. In our previous series of 137 cases, nodal disease was present in 83 (60.6 per cent) patients, comprising $23 \mathrm{~N}_{1}$ cases, 46 $\mathrm{N}_{2}$ cases and $14 \mathrm{~N}_{3}$ cases. Regional recurrence alone occurred in 11.7 per cent of cases, and locoregional recurrence in 2.2 per cent. ${ }^{7}$ Table I summarises the results of literature published to date. ${ }^{4,7,10-23}$ 


\begin{tabular}{|c|c|c|c|c|}
\hline \multicolumn{5}{|c|}{$\begin{array}{l}\text { TABLE I } \\
\text { LARYNGECTOMY }\end{array}$} \\
\hline Study & Pts $(n)$ & Site (pts; $n)$ & Time period & Survival rate \\
\hline Pearson et al. ${ }^{4}$ & 7 & Larynx & $3 \mathrm{mth}$ to $5 \mathrm{yr} \mathrm{FU}$ & $100 \%$ \\
\hline Singh \& Hardcastle ${ }^{12}$ & 4 & $\begin{array}{l}\text { Larynx (3) } \\
\text { Hypopharynx (1) }\end{array}$ & $1.3 \mathrm{yr}$ & $100 \%$ \\
\hline Lima et al. ${ }^{13}$ & 28 & Larynx & 1990-1994 & $85 \%$ (3-yr disease-free survival) \\
\hline Andrade et al. ${ }^{14}$ & 42 & Larynx (37) & $1988-1995$ & $81.7 \%$ larynx (5-yr overall survival) \\
\hline Thakar et al. ${ }^{11}$ & 28 & $\begin{array}{l}\text { Larynx (16) } \\
\text { Hypopharynx (12) }\end{array}$ & $1996-2005$ & $74 \%$ (4-yr disease-free survival) \\
\hline Shenoy et al. ${ }^{15}$ & 54 & $\begin{array}{l}\text { Larynx (14) } \\
\text { Hypopharynx (40) }\end{array}$ & $1991-1996$ & $\begin{array}{l}74 \% \text { larynx ( } 3 \text {-yr disease-free survival) } \\
66 \% \text { pyriform fossa, medial wall ( } 5 \text {-yr survival) } \\
54 \% \text { pyriform fossa, lateral wall ( } 5 \text {-yr survival) }\end{array}$ \\
\hline Maamoun et al. ${ }^{16}$ & 39 & Larynx & $1998-2001$ & $76 \%$ (2-yr disease-free survival) \\
\hline Kavabata et al. ${ }^{17}$ & 15 & $\begin{array}{l}\text { Larynx (12) } \\
\text { Hypopharynx (1) } \\
\text { Oropharynx (2) }\end{array}$ & $1993-2002$ & $81.6 \%$ (3-yr actuarial survival) \\
\hline Aslan $e t a l .{ }^{10}$ & 74 & Larynx & $1989-2000$ & $\begin{array}{l}65.8 \% \text { transglottis ( } 5 \text {-yr survival) } \\
53.8 \% \text { supraglottis }(5 \text {-yr survival) } \\
20 \% \text { subglottis }(5 \text {-yr survival) }\end{array}$ \\
\hline Qi J et al. ${ }^{18}$ & 12 & Larynx & $1990-1996$ & $\begin{array}{l}75 \% \text { (3-yr survival) } \\
66.7 \% \text { (5-yr survival) }\end{array}$ \\
\hline Ozüdoğru et al. ${ }^{19}$ & 20 & $\begin{array}{l}\text { Larynx (18) } \\
\text { Pyriform fossa (2) }\end{array}$ & & $\begin{array}{l}81.2 \% \text { (2-yr survival) } \\
64.2 \% \text { (3-yr survival) }\end{array}$ \\
\hline Tang et al. ${ }^{20}$ & 14 & $\begin{array}{l}\text { Larynx (10) } \\
\text { Pyriform fossa ( } 3 \text { ) } \\
\text { Oesophagus (1) }\end{array}$ & & $78.6 \%$ (2-yr survival) \\
\hline Han et l. $^{21}$ & 28 & Larynx & & $\begin{array}{l}78.6 \% \text { (3-yr survival) } \\
68.4 \% \text { (5-yr survival) }\end{array}$ \\
\hline Terris et $a l^{22}$ & 22 & Larynx & $1980-1994$ & $90.9 \%$ (local control rate ) \\
\hline Bernáldez et al. ${ }^{23}$ & 87 & $\begin{array}{l}\text { Larynx }(63) \\
\text { Pyriform fossa (22) }\end{array}$ & $1991-1998$ & $75.8 \%$ (cause-specific survival) \\
\hline Pradhan et al. ${ }^{7}$ & 137 & $\begin{array}{l}\text { 1ongue base }(2) \\
\text { Larynx (45) } \\
\text { Pyriform fossa (92) }\end{array}$ & 1989-1999 & $70.1 \%$ (alive \& disease-free after $12-104 \mathrm{mth}$ FU) \\
\hline
\end{tabular}

Pts $=$ patients; $\mathrm{mth}=$ months; $\mathrm{yr}=$ years; $\mathrm{FU}=$ follow up

\section{Presence of speech}

The advantages of near-total laryngectomy are its high success rate, lung-powered speech, maintenance-free shunt and excellent speech outcomes. The incidence of successful speech outcomes ranges from 74 to 100 per cent. ${ }^{4,8,9,11,12,14-18,20,21,23-34}$ The results of various studies are summarised in Table II.

In the previously published series, we analysed the speech outcomes of 150 patients with carcinoma of the larynx and pyriform fossa who underwent neartotal laryngectomy at our institution. Intelligible speech was acquired by 90 per cent of these patients. Similarly extended near-total laryngectomy with or without patch pharyngoplasty also developed successful speech. ${ }^{34}$ This speech was maintenance-free. None of the published series reported loss of voice subsequent to its initial establishment.

Satisfactory voice outcomes are generally maintained in patients receiving post-operative radiotherapy. ${ }^{8,9,17,22}$ In our previous experience of 94 patients receiving radiotherapy, 88 (93.7 per cent) completed their treatment without any adverse outcome. ${ }^{7}$

\section{Quality of speech}

During our speech analysis of 150 patients treated at our institution, speech quality was subjectively

\begin{tabular}{|c|c|c|}
\hline \multicolumn{3}{|c|}{$\begin{array}{l}\text { PUBLISHED NEAR-TOTAL LARYNGECTOMY SPEECH } \\
\text { OUTCOMES }\end{array}$} \\
\hline \multirow[t]{2}{*}{ Study } & \multicolumn{2}{|c|}{ Pts with sat $\mathrm{SO}$ (of total pts) } \\
\hline & $n$ & $\%$ \\
\hline Singh \& Hardcastle ${ }^{12}$ & $4 / 4$ & 100 \\
\hline Hoasjoe $\mathrm{et} \mathrm{al.}^{24}$ & $11 / 11$ & 100 \\
\hline Desanto et $a l^{25}$ & $29 / 39$ & 74 \\
\hline Pearson et al. ${ }^{4}$ & $7 / 7$ & 100 \\
\hline Levine et $_{\text {al. }}^{26}$ & $9 / 11$ & 82 \\
\hline Han et al. ${ }^{21}$ & $27 / 28$ & 96.4 \\
\hline Chandrachud et al. ${ }^{27}$ & $11 / 11$ & 100 \\
\hline Su \& Hwang ${ }^{28}$ & $18 / 21$ & 86 \\
\hline Shan $^{29}$ & $10 / 10$ & 100 \\
\hline Tang et al. ${ }^{20}$ & $12 / 14$ & 85.7 \\
\hline Suits et al. ${ }^{30}$ & $30 / 39$ & 76 \\
\hline Shenoy et al. ${ }^{31}$ & $23 / 29$ & 79.3 \\
\hline Thakar et al. ${ }^{11}$ & $23 / 28$ & 82 \\
\hline Shenoy et al. ${ }^{15}$ & $44 / 54$ & 81 \\
\hline Cakli et al. ${ }^{32}$ & $19 / 23$ & 82.6 \\
\hline Andrade et $a l^{14}$ & $35 / 42$ & 83.3 \\
\hline Maamoun et al. 16 & $31 / 38$ & 81.6 \\
\hline Qi et $a l^{18}$ & $10 / 12$ & 83.3 \\
\hline Aslan et al. ${ }^{9}$ & $90 / 127$ & 70.8 \\
\hline Pearson $\mathrm{et} \mathrm{al.}^{8}$ & $191 / 225$ & 85 \\
\hline Kavabata et al. ${ }^{17}$ & $12 / 15$ & 80 \\
\hline Bernáldez et al. ${ }^{23}$ & $61 / 79$ & 77.2 \\
\hline $\mathrm{Su}^{33}$ & $50 / 66$ & 76 \\
\hline Pradhan et al. ${ }^{34}$ & $135 / 150$ & 90 \\
\hline
\end{tabular}

Pts $=$ patients; sat $\mathrm{SO}=$ satisfactory speech outcome 
divided into three categories depending upon ease and fluency. Speech was graded as excellent when patients were able to speak full sentences effortlessly. A grade of 'fair' was allotted when patients spoke short sentences with some effort. A grade of 'poor' was given when speech was intelligible but consisted of a breathy whisper requiring considerable effort.

Out of a total of 135 patients ( 90 per cent) developing functional speech, 113 (75.3 per cent) were graded as excellent, 16 (10.6 per cent) as fair and six (4 per cent) as poor (Table III).

We also analysed speech quality objectively using clinical speech voice software. Voice analysis was done three months post-treatment and was compared with matched patients who had undergone total laryngectomy with tracheoesophageal puncture prosthesis. Of the various parameters studied, patients with neartotal laryngectomy performed better in terms of fundamental frequency, frequency range and maximum frequency, with results approaching those for the normal voice. This provides strong evidence for the superiority of biological shunting over the tracheoesophageal puncture prosthesis (Table IV). ${ }^{34}$

Similarly, Singh examined eight patients with neartotal laryngectomy, using electrolaryngography, and found functional similarities between the neoglottis and the normal glottis. ${ }^{35}$ In a subsequent study, this same author used electrolaryngography to compare the fundamental frequencies of 15 near-total laryngectomy patients with those of 17 oesophageal speakers and 11 normal speakers. The mean fundamental frequencies of the neoglottal and male oesophageal speakers were higher than those of the normal group. The fundamental frequency of the single female neoglottal speaker was higher than the normal mean, but all female oesophageal speakers had a lower frequency compared with normal female speakers. ${ }^{6}$

Hoasjoe et al. compared near-total laryngectomy voice characteristics to those of normal laryngeal voice. $^{24}$ They found that the near-total laryngectomy speakers had a generally restricted fundamental frequency, reduced intensity and limited phonation

\section{TABLE III}

NEAR-TOTAL LARYNGECTOMY SPEECH OUTCOMES

\begin{tabular}{lr}
\hline Outcome & Pts $(n)$ \\
\hline Success* & \\
Excellent speech & 113 \\
Fair speech & 16 \\
Poor speech & 6 \\
Total patients & 135 \\
Failure & \\
Shunt stenosis & 9 \\
Shunt breakdown & 2 \\
Adynamic shunt & 1 \\
Cause unknown & 3 \\
Total failed patients & 15 \\
\hline
\end{tabular}

${ }^{*}$ Found in $90 \%$ of patients; ${ }^{\dagger}$ found in $10 \%$ of patients. Pts $=$ patients duration, compared with the normal laryngeal speakers. ${ }^{24}$

\section{Complications}

The major complications of near-total laryngectomy are shunt stenosis and aspiration. Another complication related to the procedure is pharyngocutaneous fistula. Table V summarises reported complication rates.

Shunt stenosis. Shunt stenosis adversely affects voice outcomes. A shunt of adequate diameter is necessary to achieve a satisfactory voice. Stenosis of the shunt can be avoided by taking particular care when creating the shunt. The minimum shunt diameter required to prevent stenosis is said to be $6 \mathrm{~mm}$. We recommend using a 14 French Foley's catheter or a number six red rubber catheter as a guide when fashioning the shunt. If the mucosa is insufficient to create a shunt of adequate diameter, it can be augmented using the mucosa from the adjoining pyriform sinus. ${ }^{4,7}$ In cases of stenosis, several dilatations may be attempted. The reported incidence of shunt stenosis varies. Su identified shunt stenosis in 20 per cent of patients, but also reported that 83.3 per cent of stenosed cases could be corrected surgically using a sternohyoid myofacial flap and skin graft. ${ }^{33} \mathrm{We}$ ourselves have no experience with this technique. Kavabata et al. reported shunt stenosis in one of 15 cases who failed to attain speech. ${ }^{17}$ In our previous series, the incidence of shunt stenosis was 6.6 per cent. $^{7}$

Aspiration. The shunt formed during near-total laryngectomy is a dynamic shunt. This acts as a valve allowing air inflow into the shunt, powered by the lungs, and producing vibration of the neoglottis. Aspiration is prevented by contraction of laryngeal musculature which is vagally innervated. The preservation of the recurrent laryngeal nerve is the most important step to preventing aspiration. Although rates vary in different series, the risk of major aspiration is generally quite low. Aslan et al. reported aspiration in 26.7 per cent of cases; however, the incidence of major aspiration was 5.5 per cent, and this could be completely rectified surgically in 57.1 per cent of cases. ${ }^{9}$ In our own previous series, minor aspiration developed in 12.4 per cent of cases, while major aspiration requiring completion laryngectomy occurred in only 0.7 per cent. ${ }^{7}$ Maamoun et al. reported an aspiration rate of 33.3 per cent, but all cases were of a transient nature and resolved spontaneously. ${ }^{16}$ Other studies have reported aspiration rates ranging from 10 to 42 per cent. ${ }^{17,23,30,32,33,36,37}$

Pharyngocutaneous fistula. Theoretically, one would expect the incidence of pharyngocutaneous fistula to be slightly higher following near-total laryngectomy compared with total laryngectomy, due to the former procedure's uneven suture line caused by the invagination of the voice shunt in the neopharynx. Fortunately, most cases of pharyngocutaneous fistula settle with conservative treatment. Kavabata et al. reported a pharyngocutaneous fistula incidence of 53 per cent in their series, 
TABLE IV

VOICE ANALYSIS: TRACHEOESOPHAGEAL PUNCTURE PROSTHESIS VS NEAR-TOTAL LARYNGECTOMY

\begin{tabular}{|c|c|c|c|c|}
\hline Parameter & Procedure & Mean & SD & $p^{*}$ \\
\hline \multirow[t]{2}{*}{ Fundamental frequency $(\mathrm{Hz})$} & TEP & 120.95 & 41.75 & 0.000 \\
\hline & NTL & 162.32 & 54.46 & \\
\hline \multirow[t]{2}{*}{ Maximum frequency $(\mathrm{Hz})$} & TEP & 159.89 & 57.63 & 0.000 \\
\hline & NTL & 214.04 & 73.18 & \\
\hline \multirow[t]{2}{*}{ Minimum frequency $(\mathrm{Hz})$} & TEP & 91.60 & 37.25 & 0.70 \\
\hline & NTL & 108.47 & 44.38 & \\
\hline \multirow[t]{2}{*}{ Frequency range $(\mathrm{Hz})$} & TEP & 68.92 & 54.13 & 0.019 \\
\hline & NTL & 105.57 & 80.45 & \\
\hline \multirow{2}{*}{ Maximum intensity (dB) } & TEP & 70.32 & 8.79 & 0.633 \\
\hline & NTL & 71.17 & 6.94 & \\
\hline \multirow[t]{2}{*}{ Minimum intensity $(\mathrm{dB})$} & TEP & 38.55 & 19.66 & 0.49 \\
\hline & NTL & 41.69 & 20.75 & \\
\hline \multirow{2}{*}{ Maximum phonation time (Seconds) } & TEP & 4.43 & 3.75 & 0.314 \\
\hline & NTL & 5.39 & 4.57 & \\
\hline \multirow[t]{2}{*}{ Jitter } & TEP & 1.46 & 0.868 & 0.738 \\
\hline & NTL & 1.36 & 0.90 & \\
\hline \multirow[t]{2}{*}{ Shimmer } & TEP & 5.84 & 2.34 & 0.843 \\
\hline & NTL & 5.67 & 2.66 & \\
\hline \multirow[t]{2}{*}{$\mathrm{S} / \mathrm{Z}$ ratio } & TEP & 1.11 & 1.90 & 0.594 \\
\hline & NTL & 1.40 & 1.92 & \\
\hline \multirow[t]{2}{*}{ Harmonic-to-noise ratio } & TEP & 14.50 & 5.32 & 0.669 \\
\hline & NTL & 15.30 & 5.45 & \\
\hline \multirow{2}{*}{ Sound-to-noise ratio } & TEP & 31.41 & 5.00 & 0.702 \\
\hline & NTL & 14.10 & 5.28 & \\
\hline
\end{tabular}

${ }^{*} t$-test. $\mathrm{SD}=$ standard deviation; $\mathrm{TEP}=$ tracheoesophageal puncture prosthesis; $\mathrm{NTL}=$ near total laryngectomy; $\mathrm{S} / \mathrm{Z}$ ratio is the ratio of voiceless sound to voiced sound. Normal value is 1.4

but none of these cases required surgical correction. ${ }^{17}$ In our previous study, 8.7 per cent of our patients developed a major fistula, and the incidence of leakage requiring surgical intervention was 3.6 per cent. $^{7}$

\section{Post-radiation failures}

Pearson et al. reported a cancer recurrence rate of 20 per cent in their near-total laryngectomy patients who had previously undergone radiotherapy. ${ }^{8}$ Thus, they concluded that previous radiotherapy was a relative contraindication to near-total laryngectomy.

In our previous series of 137 patients, 15 had received prior radiotherapy. ${ }^{7}$ The local control rate for post-radiotherapy salvage was 93.3 per cent, thus confirming the oncological safety of the procedure in this setting. The complication rate was slightly higher in this group. Two out of 13 patients (15.4 per cent) developed a major pharyngocutaneous fistula: one of these patients died and the other lost the shunt.

Therefore, in patients who have received previous radiotherapy, judicious selection must be exercised.

\section{Current status}

Near-total laryngectomy was first described by Pearson et al. in 1980, in a small series of seven patients with early glottic cancers. However, the procedure did not gain popularity because of its perceived complexity and unproven oncological safety.

There are now various publications, from many authors around the world, establishing that near-total laryngectomy has acceptable oncological safety, a high rate of successful post-operative speech, and an acceptable complication rate. Therefore, the practising head and neck surgeon should be conversant with the

\begin{tabular}{|c|c|c|c|}
\hline \multicolumn{4}{|c|}{$\begin{array}{c}\text { TABLE V } \\
\text { PUBLISHED NEAR-TOTAL LARYNGECTOMY COMPLICATION RATES }\end{array}$} \\
\hline Study & Shunt stenosis $(\%)$ & Aspiration (\%) & Pharyngocutaneous fistula (\%) \\
\hline $\mathrm{Su}^{33}$ & $13 / 66(20)$ & $4 / 66(6)$ & - \\
\hline Kavabata et al. ${ }^{17}$ & & $4 / 15(26.6)$ & $8 / 15(53)$ \\
\hline Aslan et al. ${ }^{9}$ & & $34 / 127$ (26.8) & \\
\hline Maamoun et al. ${ }^{16}$ & & $13 / 39(33.3)$ & $9 / 39(23.1)$ \\
\hline Bernáldez et $a l^{23}$ & & $16 / 79(20.2)$ & $40 / 82(48)$ \\
\hline Gavilán et al. ${ }^{36}$ & & $5 / 49(10.2)$ & $23 / 49(46.9)$ \\
\hline Cakli et $a l^{32}$ & & (42) & $5 / 23(21.7)$ \\
\hline Prim et al. ${ }^{37}$ & & (13.9) & $(58.9)$ \\
\hline Suits et al. ${ }^{30}$ & & $8 / 39$ (21) & \\
\hline Pradhan et al. ${ }^{7}$ & 9/137 (6.6) & 18/137 (13.1) & $12 / 137(8.7)$ \\
\hline
\end{tabular}

Data represent patient numbers (percentages). - =patients with complications $/ \mathrm{n}$. $\mathrm{n}=$ no of patients in the series 
procedure, given its distinct advantage of avoidance of a tracheoesophageal puncture prosthesis. We estimate that approximately 10 per cent of patients suitable for total laryngectomy are also suitable for near-total laryngectomy. The procedure involves the creation of a shunt from the patient's uninvolved tissues, which has the advantage of being maintenance-free and dynamic.

Near-total laryngectomy should be considered as an alternate to total laryngectomy in selected individuals. Surgeons should train themselves in the procedure, so that it acquires the prominence it deserves.

\section{Conclusion}

Near-total laryngectomy should be considered as an alternative to total laryngectomy in selected patients with well lateralised, advanced laryngeal and hypopharyngeal cancers.

Although patients are left with a permanent tracheostoma, lung-powered speech is made possible by fashioning a voice shunt from the patient's unremoved tissues. This shunt is dynamic, and maintenance-free once established. The incidence of successful postoperative speech is as high for near-total laryngectomy patients as for those using a tracheoesophageal puncture prosthesis. Furthermore, objective speech assessment suggests that the speech outcomes of the former procedure are superior to those of the latter.

Finally, the oncological safety of near-total laryngectomy has been established by various studies worldwide.

\section{References}

1 Silver CE. Surgery for cancer of the larynx and related structures. New York: Churchill Livingstone, 1981

2 Müller R, Paneff J, Köllner V, Koch R. Quality of life of patients with laryngeal carcinoma: a post-treatment study. Eur Arch Otorhinolaryngol 2001;258:276-80

3 Gates GA, Ryan W, Cooper JC Jr, Lawlis GF, Cantu E, Hayashi $\mathrm{T}$ et al. Current status of laryngectomee rehabilitation: I. Results of therapy. Am J Otolaryngol 1982;3:1-7

4 Pearson BW, Woods RD 2nd, Hartman DE. Extended hemilaryngectomy for T3 glottic carcinoma with preservation of speech and swallowing. Laryngoscope 1980;90:1950-61

5 Pearson BW. Subtotal laryngectomy. Laryngoscope 1981;91: 1904-12

6 Singh W, Ainsworth WA. Computerised measurement of fundamental frequency in Scottish neoglottal patients. Folia Phoniatr (Basel) 1992;44:231-7

7 Pradhan SA, D’Cruz AK, Pai PS, Mohiyuddin A. Near-total laryngectomy in advanced laryngeal and pyriform cancers. Laryngoscope 2002;112:375-80

8 Pearson BW, DeSanto LW, Olsen KD, Salassa JR. Results of near-total laryngectomy. Ann Otol Rhinol Laryngol 1998;107: $820-5$

9 Aslan I, Baserer N, Yazicioglu E, Biliciler N, Hafiz G, Tinaz M et al. The functional and oncologic effectiveness of near-total laryngectomy. Am J Otolaryngol 2002;23:196-20

10 Aslan I, Baserer N, Yazicioglu E, Oysu C, Tinaz M, Kiyak E et al. Near-total laryngectomy for laryngeal carcinomas with subglottic extension. Arch Otolaryngol Head Neck Surg 2002; 128: $177-80$

11 Thakar A, Bahadur S, Toran KC, Mohanti BK, Julka PK. Analysis of oncological and functional failures following neartotal laryngectomy. J Laryngol Otol 2009;123:327-32

12 Singh W, Hardcastle P. Near-total laryngectomy with myomucosal valved neoglottis. J Laryngol Otol 1985;99:581-8
13 Lima RA, Freitas EQ, Kligerman J, Paiva FP, Dias FL, Barbosa MM et al. Near-total laryngectomy for treatment of advanced laryngeal cancer. Am J Surg 1997;174:490-1

14 Andrade RP, Kowalski LP, Vieira LJ, Santos CR. Survival and functional results of Pearson's near-total laryngectomy for larynx and pyriform sinus carcinoma. Head Neck 2000;22:12-16

15 Shenoy AM, Sridharan S, Srihariprasad AV, Reddy BK, Anand VT, Premalatha BS et al. Near-total laryngectomy in advanced cancers of the larynx and pyriform sinus: a comparative study of morbidity and functional and oncological outcomes. Ann Otol Rhinol Laryngol 2002;111:50-6

16 Maamoun SI, Amira G, Younis A. Near total laryngectomy: a versatile approach for voice restoration in advanced T3 and T4 laryngeal cancer: functional results and survival. J Egypt Natl Canc Inst 2004;16:15-21

17 Kavabata NK, Silva Neto AL, Gonçalves AJ, Alcadipani FA, Menezes MB. A nine-year institutional experience with neartotal laryngectomy. Am J Surg 2004;188:111-14

18 Qi J, Fang R, Wang C, Chen R. Long-term follow-up result of near-total laryngectomy in senile patients with laryngeal carcinoma [in Chinese]. Lin Chuang Er Bi Yan Hou Ke Za Zhi 2003; 17:714-15

19 Ozüdoğru E, Cingi E, Cakli H, Keçik MC, Cingi C, Gürbüz MK. Patient selection for near-total laryngectomy and oncologic results [in Turkish]. Kulak Burun Bogaz Ihtis Derg 2002;9:121-5

20 Tang P, Qi Y, Tu G. Near-total laryngectomy in the treatment of advanced laryngeal and hypopharyngeal carcinoma [in Chinese]. Zhonghua Er Bi Yan Hou Ke Za Zhi 1994;29:10-12

21 Han Y, Zhang K, Yu F, Dong Y, Zhan X, Sha Q. Pearson technique in the treatment of advanced laryngeal cancer [in Chinese]. Lin Chuang Er Bi Yan Hou Ke Za Zhi 2003;17:328-9

22 Terris DJ, Fee WE Jr, Goffinet DR. Potential success of neartotal laryngectomy despite postoperative radiation therapy. Laryngoscope 1996;106:1152-6

23 Bernáldez R, García-Pallarés M, Morera E, Lassaletta L, Del Palacio A, Gavilán J. Oncologic and functional results of neartotal laryngectomy. Otolaryngol Head Neck Surg 2003;128:700-5

24 Hoasjoe DK, Martin GF, Doyle PC, Wong FS. A comparative acoustic analysis of voice production by near-total laryngectomy and normal laryngeal speakers. J Otolaryngol 1992;21:39-43

25 DeSanto LW, Pearson BW, Olsen KD. Utility of near-total laryngectomy for supraglottic, pharyngeal, base-of-tongue, and other cancers. Ann Otol Rhinol Laryngol 1989;98:2-7

26 Levine PA, Debo RF, Reibel JF. Pearson near-total laryngectomy: a reproducible speaking shunt. Head Neck 1994;16:323-5

27 Chandrachud HR, Chaurasia MK, Sinha KP. Subtotal laryngectomy with myomucosal shunt. J Laryngol Otol 1989;103:504-7

$28 \mathrm{Su}$ CY, Hwang CF. Near-total laryngopharyngectomy with pectoralis major myocutaneous flap in advanced pyriform carcinoma. J Laryngol Otol 1993;107:817-20

29 Shan X. Voice rehabilitation by mucosa tube performed after near-total and total laryngectomy for the treatment of advanced laryngeal carcinoma [in Chinese]. Lin Chuang Er Bi Yan Hou Ke Za Zhi 1998;12:540-2

30 Suits GW, Cohen JI, Everts EC. Near-total laryngectomy. Patient selection and technical considerations. Arch Otolaryngol Head Neck Surg 1996;122:473-5

31 Shenoy AM, Plinkert PK, Nanjundappa N, Premalata S, Arunodhay GR. Functional utility and oncologic safety of neartotal laryngectomy with tracheopharyngeal speech shunt in a Third World oncologic center. Eur Arch Otorhinolaryngol 1997; 254:128-32

32 Cakli H, Ozudogru E, Cingi E, Kecik C, Gürbüz K. Near total laryngectomy: the problems influencing functions and their solutions. Eur Arch Otorhinolaryngol 2005;262:99-102

$33 \mathrm{Su}$ CY. Aspiration and speech shunt stenosis in near-total laryngectomy patients. Eur Arch Otorhinolaryngol 1997;254:401-4

34 Pradhan SA, D'Cruz AK, Pai PS. Near-total laryngectomy. Asian J Surg 2002;25:27-34

35 Singh W. Electrolaryngography in near-total laryngectomy with myo-mucosal valved neoglottis. J Laryngol Otol 1987;101: $815-18$

36 Gavilán J, Herranz J, Prim J, Rabanal I. Speech results and complications of near-total laryngectomy. Ann Otol Rhinol Laryngol 1996;105:729-33

37 Prim Espada MP, Rabanal Retolaza I, de Diego Sastre JI, Gavilán Bouzas J. "Near-total" laryngectomy: functional results [in Spanish]. Acta Otorrinolaringol Esp 1996;47:135-7 
Address for correspondence:

Dr A K D’Cruz,

Director, Tata Memorial Hospital,

Professor and Surgeon,

Chief, Head Neck Services,

Tata Memorial Hospital, Parel,

Mumbai 40001, India
Fax: +9122 24158989

E-mail: docdcruz@gmail.com

Dr A K D'Cruz takes responsibility for the integrity of the content of the paper

Competing interests: None declared 